\title{
Indicadores para diagnóstico, monitoramento e avaliação de programas sociais no Brasil*
}

Paulo de Martino Jannuz:i $i$

\section{Introdução}

O interesse pela temática dos indicadores sociais e sua aplicação nas atividades ligadas ao planejamento governamental e ao ciclo de formulação e avaliação de políticas públicas vêm crescendo no País, nas diferentes esferas de governo e nos diversos fóruns de discussão dessas questões. Tal fato deve-se, em primeiro lugar, certamente, às mudanças institucionais por que a administração pública tem passado no País, em especial com a consolidação da sistemática do planejamento plurianual, com o aprimoramento dos controles administrativos dos ministérios, com a mudança da ênfase da auditoria dos Tribunais de Contas da avaliação da conformidade legal para a avaliação do desempenho dos programas, com a reforma gerencial da gestão pública em meados dos anos 1990 (Garcia, 2001. Costa; Castanhar, 2003). Esse interesse crescente pelo uso de indicadores na administração pública também está relacionado ao aprimoramento do controle social do Estado brasileiro nos últimos 20 anos. A mídia, 
os sindicatos e a sociedade civil passaram a ter maior poder de fiscalização do gasto público e a exigir o uso mais eficiente, eficaz e efetivo dele, demandando a reorganização das atividades de planejamento em bases mais técnicas.

Também tem contribuído para a disseminação do uso dos indicadores o acesso crescentemente facilitado às informações mais estruturadas - de natureza administrativa e estatística - que as novas tecnologias de informação e comunicação viabilizam. Dados cadastrais antes esquecidos em armários e fichários passam a transitar pela Internet, transformando-se em informação estruturada para análise e tomada de decisão. Dados estatísticos antes inacessíveis em enormes arquivos digitais passam a ser "customizados" na forma de tabelas, mapas e modelos quantitativos construídos por usuários não especializados. Sem dúvida, a Internet, os CD-ROMs inteligentes, os arquivos de microdados potencializaram muito a disseminação da informação administrativa compilada por órgãos públicos e a informação estatística produzida pelas agências especializadas.

É com o objetivo de apresentar como essas informações estruturadas podem ser empregadas nas diferentes etapas do ciclo de formulação e avaliação de prog ramas públicos que se apresenta este texto. Para isso, inicialmente, apresentam-se, nas duas primeiras seções, os aspectos conceituais básicos acerca dos indicadores sociais, as suas propriedades e as formas de classificá-los. Depois, discute-se uma proposta de estruturação de um sistema de indicadores para subsidiar o processo de formulação e avaliação de políticas e programas públicos no País.

\section{Indicadores nas políticas públi- cas: conceito e suas propriedades}

No campo aplicado das políticas públicas, os indicadores sociais são medidas usadas para permitir a operacionalização de um conceito abstrato ou de uma demanda de interesse programático. Os indicadores apontam, indicam, aproximam, traduzem em termos operacionais as dimensões sociais de interesse definidas a partir de escolhas teóricas ou políticas realizadas anteriormente. Prestam-se a subsidiar as atividades de planejamento público e a formulação de políticas sociais nas diferentes esferas de governo, possibilitam o monitoramento das condições de vida e bem-estar da população por parte do poder público e da sociedade civil e permitem o aprofundamento da investigação acadêmica sobre a mudança social e sobre os determinantes dos diferentes fenômenos sociais (Miles, 1985. NaÇÕES UNIDAS, 1988). Taxas de analfabetismo, rendimento médio do trabalho, taxas de mortalidade infantil, taxas de desemprego, índice de Gini e proporção de crianças matriculadas em escolas são, nesse sentido, indicadores sociais, ao traduzirem em cifras tangíveis e operacionais várias das dimensões relevantes, específicas e dinâmicas da realidade social.

O processo de construção de um indicador social, ou melhor, de um sistema de indicadores sociais, para uso no ciclo de políticas públicas inicia-se a partir da explicitação da demanda de interesse programático, tais como a proposição de um programa para ampliação do atendimento à saúde, a redução do déficit habitacional, o aprimoramento do desempenho escolar e a melhoria das condições de vida de uma comunidade. A partir da definição desse objetivo programático, busca-se, então, delinear as dimensões, os 
componentes ou as ações operacionais vinculadas. Para o acompanhamento dessas ações em termos da eficiência no uso dos recursos, da eficácia no cumprimento de metas e da efetividade dos seus desdobramentos sociais mais abrangentes e perenes, buscam-se dados administrativos (gerados no âmbito dos programas ou em outros cadastros oficiais) e estatísticas públicas (produzidas pelo IBGE e outras instituições), que, reorganizados na forma de taxas, proporções, índices ou mesmo em valores absolutos, transformam-se em indicadores sociais (Figura 1). Os indicadores guardam, pois, relação direta com o objetivo programático original, na forma operacionalizada pelas ações e viabilizada pelos dados administrativos e pelas estatísticas públicas disponíveis.
A relevância para a agenda político-social é a primeira e uma das propriedades fundamentais de que devem gozar os indicadores escolhidos em um sistema de formulação e avaliação de programas sociais específicos. Indicadores como a taxa de mortalidade infantil, a proporção de crianças com baixo peso ao nascer e a proporção de domicílios com saneamento adequado são, por exemplo, relevantes e pertinentes para acompanhamento de programas no campo da saúde pública no Brasil, na medida em que podem responder à demanda de monitoramento da agenda governamental das prioridades definidas na área nas últimas décadas. Indicadores de pobreza (no sentido de carência de rendimentos), por outro lado, só vieram a ser regularmente produzidos quando

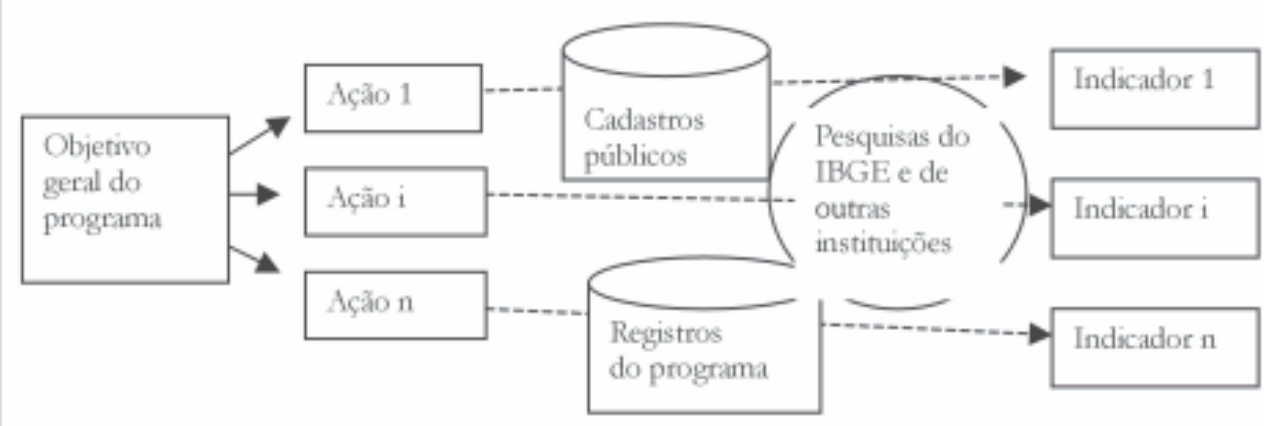

Figura 1: Construção de sistema de indicadores para ciclo de políticas públicas

A escolha de indicadores sociais para uso no processo de formulação e avaliação de políticas públicas deve ser pautada pela aderência deles a um conjunto de propriedades desejáveis e pela lógica estruturante da aplicação, que definirá a tipologia de indicadores mais adequada (JANNUZZI, 2001). No Quadro 1, estão relacionadas 12 propriedades cuja avaliação de aderência $(+)$ e de não aderência ou indiferença deveria determinar o uso, ou não, do indicador para os propósitos almejados. programas e ações focalizados em grupos mais vulneráveis entraram na agenda da política social, a partir dos anos 1980.

Validade é outro critério fundamental na escolha de indicadores, pois é desejável que se disponha de medidas tão "próximas" quanto possível do conceito abstrato ou da demanda política que lhes deram origem. Em um programa de combate à fome, por exemplo, indicadores antropométricos ou do padrão de consumo familiar de alimentos certamente gozam de 
maior validade que uma medida baseada na renda disponível, como a proporção de indigentes. Afinal, índice de massa corpórea, baixo peso ao nascer ou quantidade de alimentos efetivamente consumidos estão mais diretamente relacionados à nutrição adequada e à desnutrição que à disponibilidade de rendimentos. Por outro lado, é operacionalmente mais complexo e custoso levantar informações para o
- que aqueles passíveis de serem obtidos a partir de pesquisas de vitimização, em que se questionam os indivíduos acerca de agravos sofridos em seu meio em determinado período. Naturalmente, mesmo nessas pesquisas, as pessoas podem-se sentir constrangidas a revelar situações de violência pessoal sofrida, por exemplo, no contexto doméstico, no assédio sexual ou na discriminação por raça e/ou cor.

Quadro 1: Avaliação da aderência dos indicadores às propriedades desejáveis

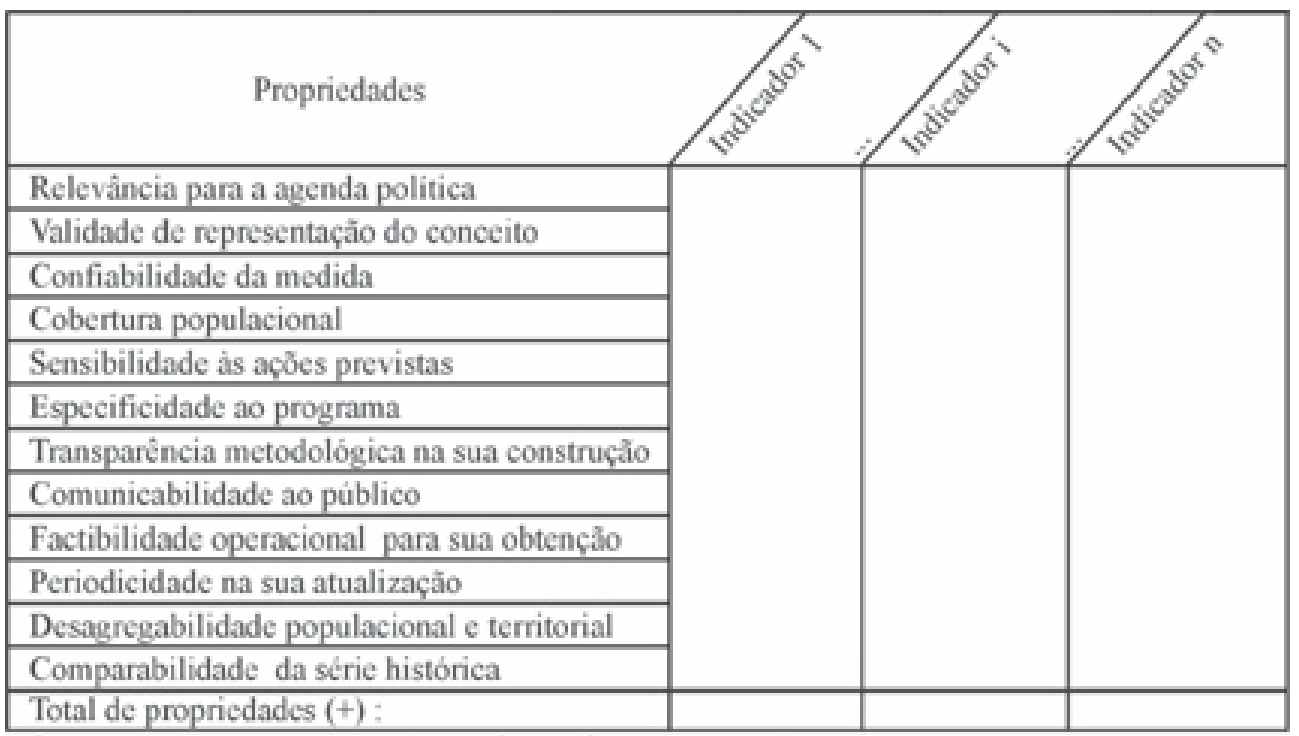

Obs:: Atribuir + quando a propriedade for verificada para $o$ indicador

cálculo desses indicadores de maior validade, comprometendo o uso deles para fins de monitoramento periódico do grau de "fome" na comunidade (daí o uso de indicadores de rendimento como medidas de acompanhamento).

Confiabilidade da medida é outra propriedade importante para legitimar o uso do indicador. $\mathrm{Na}$ avaliação do nível de violência em uma comunidade, por exemplo, indicadores baseados nos registros de ocorrências policiais ou mesmo de mortalidade por causas violentas tendem a ser menos confiáveis - e menos válidos
Sempre que possível, deve-se procurar empregar indicadores de boa cobertura territorial ou populacional, que sejam representativos da realidade empírica em análise. Essa é uma das características interessantes dos indicadores sociais produzidos a partir dos censos demográficos, o que os tornam tão importantes para o planejamento público no País. Mas mesmo indicadores de cobertura parcial podem ser úteis. Os indicadores de mercado de trabalho construídos a partir das bases de dados administrativos do Ministério do Trabalho, por exemplo, não retratam a 
dinâmica conjuntural do mercado de trabalho brasileiro, já que se referem apenas ao mercado de trabalho formal. Ainda assim, esses indicadores aportam conhecimento relevante acerca da dinâmica conjuntural da economia e do emprego, em especial em âmbito municipal.

Sensibilidade e especificidade são propriedades que também devem ser avaliadas quando da escolha de indicadores para a elaboração de um sistema de monitoramento e avaliação de programas públicos. Afinal, é importante dispor de medidas sensíveis e específicas às ações previstas nos programas, que possibilitem avaliar rapidamente os efeitos (ou nãoefeitos) de determinada intervenção. Taxa de evasão ou freqüência escolar, por exemplo, são medidas sensíveis e com certa especificidade para monitoramento de programas de transferência de renda, na medida em que se espera verificar, em curto prazo, nas comunidades a tendidas por tais programas, maior engajamento das crianças na escola, como resultado direto de controles compulsórios previstos ou mesmo como conseqüência indireta da mudança de comportamento ou da necessidade familiar.

A boa prática da pesquisa social recomenda que os procedimentos de construção dos indicadores sejam claros e transparentes, que as decisões metodológicas sejam justificadas, que as escolhas subjetivas - invariavelmente freqüentes sejam explicitadas de forma objetiva. Transparência metodológica é certamente um atributo fundamental para que o indicador goze de legitimidade nos meios técnicos e científicos, ingrediente indispensável para sua legitimidade política e social. Comunicabilidade é outra propriedade importante, com a finalidade de garantir a transparência das decisões técnicas tomadas pelos administradores públicos e a compreensão delas por parte da população, dos jornalistas, dos representantes comunitários e dos demais agentes públicos. Na discussão de planos de governo, orçamento participativo, projetos urbanos, os técnicos de planejamento deveriam valer-se, tanto quanto possível, de alguns indicadores sociais mais facilmente compreendidos, como a taxa de mortalidade infantil e a renda familiar, ou que o uso sistemático já

"Indicadores sociais permitem a operacionalização de um conceito abstrato ou de uma demanda de interesse programático. Eles apontam, indicam, aproximam, traduzem em termos operacionais as dimensões sociais de interesse definidas a partir de escolhas teóricas ou políticas realizadas anteriormente"

os consolidou, como o índice de preços e a taxa de desemprego. Nessas situações, o emprego de indicadores muito complexos pode ser visto como abuso tecnocrático dos formuladores de programas, primeiro passo para o potencial fracasso na sua implementação.

A periodicidade com que o indicador pode ser atualizado e a factibilidade de sua obtenção a custos módicos são outros 
aspectos cruciais na construção e seleção de indicadores sociais para acompanhamento de qualquer programa público. Para que se possa acompanhar a mudança social, avaliar o efeito de programas sociais implementados, corrigir eventuais distorções de implementação, é necessário que se disponha de indicadores levantados com certa regularidade. Essa é uma das grandes limitações do sistema estatístico brasileiro e, a bem da verdade, de muitos países. Para algumas temáticas da política social - trabalho, por exemplo -,é possível dispor-se de boas estatísticas e indicadores de forma periódica (mensal), para alguns domínios territoriais (principais regiões metropolitanas). Para outras temáticas, em escala estadual, é possível atualizar indicadores em bases anuais, por meio da Pesquisa Nacional por Amostra de Domicílios (PNAD). Nos municípios, em geral, pela falta de recursos, organização e compromisso com a manutenção periódica dos cadastros (de contribuintes, de imóveis, de favelas, etc.), só se dispõe de informações mais abrangentes a cada dez anos, por ocasião dos censos demográficos ${ }^{1}$.

Também é preciso que os indicadores se refiram, tanto quanto possível, aos grupos sociais de interesse ou à populaçãoalvo dos programas, isto é, deve ser possível construir indicadores sociais referentes a espaços geográficos reduzidos, grupos sociodemográficos (crianças, idosos, homens, mulheres, brancos, negros, etc.), ou grupos vulneráveis específicos (famílias pobres, desempregados, analfabetos, etc.). O Censo Demográfico 2000 reflete, nesse sentido, o esforço governamental em atender novas demandas informacionais para formulação e avaliação de políticas públicas, em especial as políticas compensatórias e as voltadas à discriminação positiva. Pela primeira vez, em censos brasi- leiros, investigou-se a freqüência à creche, à educação infantil, questão fundamental na agenda de discussão da política educacional nos municípios brasileiros. A caracterização do tipo e grau de deficiência física é outro aspecto que mereceu especial atenção no levantamento, como resultado da pressão de grupos organizados interessados em implementar, de fato, os direitos assegurados na Constituição. Tentou-se, também, na fase de pré-teste do censo, aprimorar o levantamento da ascendência étnica da população, de forma a fornecer subsídios mais precisos a políticas de discriminação positiva, de acesso compensatório a bens e serviços públicos (educação superior, por exemplo) de grupos historicamente desprivilegiados (negros, por exemplo). O acesso a programas de renda mínima, como o Bolsa Escola, e outras transferências governamentais também foram objeto de maior detalhamento no censo.

A comparabilidade do indicador ao longo do tempo é uma característica desejável, de modo a permitir a inferência de tendências e a avaliar efeitos de eventuais programas sociais implementados. O ideal é que as cifras passadas sejam compatíveis do ponto de vista conceitual e com confiabilidade similar à das medidas mais recentes, o que nem sempre é possível. Afinal, também é desejável que a coleta dos dados melhore ao longo do tempo, seja pela resolução dos problemas de cobertura espacial e organização da logística de campo, como pelas mudanças conceituais que ajudem a precisar melhor o fenômeno social em questão.

Em uma perspectiva aplicada, dadas as características do sistema de produção de estatísticas públicas no Brasil, é muito raro dispor-se de indicadores sociais que gozem plenamente de todas essas 
propriedades. $\mathrm{Na}$ prática, nem sempre o indicador de maior validade é o mais confiável; nem sempre o mais confiável é o mais sensível; nem sempre o mais sensível é o mais específico; enfim, nem sempre o indicador que reúne todas essas qualidades é passível de ser obtido na escala territorial e na periodicidade requerida. $\mathrm{O}$ importante é que a escolha dos indicadores seja fundamentada na avaliação crítica das propriedades anteriormente discutidas e não simplesmente na tradição de uso deles. Há esforço significativo de diversas instituições de disponibilizar novos conteúdos e informações a partir de seus cadastros, as quais podem ser usadas para a construção de novos indicadores sociais.

\section{Taxonomia dos indicadores para fins de aplicação nas políticas públicas}

Além da observância às propriedades, a escolha de indicadores para uso no ciclo de formulação e avaliação de programas também deveria pautar-se pela natureza ou pelo tipo dos indicadores requeridos.

Há vários sistemas classificatórios para os indicadores sociais (CARley, 1985). A classificação mais comum é a divisão dos indicadores segundo a área temática da realidade social a que se referem. Há, assim, os indicadores de saúde (leitos por mil habitantes, percentual de crianças nascidas com baixo peso, por exemplo), os indicadores educacionais (taxa de analfabetismo, escolaridade média da população de 15 anos ou mais, etc.), os indicadores de mercado de trabalho (taxa de desemprego, rendimento médio real do trabalho, etc.), os indicadores demográficos (esperança de vida, etc.), os indicadores habitacionais (posse de bens duráveis, densidade de moradores por domicílio, etc.), os indicadores de segurança pública e justiça (mortes por homicídios, roubos à mão armada por cem mil habitantes, etc.), os indicadores de infra-estrutura urbana (taxa de cobertura da rede de abastecimento de água, percentual de domicílios com esgotamento sanitário ligado à rede pública, etc.), os indicadores de renda e desigualdade (proporção de pobres, índice de Gini, etc.).

Outra classificação usual corresponde à divisão dos indicadores entre objetivos e subjetivos. Os indicadores objetivos referem-se a ocorrências concretas ou a entes empíricos da realidade social, construídos a partir das estatísticas públicas disponíveis, como o percentual de domicílios com acesso à rede de água, a taxa de desemprego, a taxa de evasão escolar ou o risco de acidentes de trabalho. Os indicadores subjetivos, por outro lado, cor respondem a medidas construídas a partir da avaliação dos indivíduos ou especialistas com relação a diferentes aspectos da realidade, levantados em pesquisas de opinião pública ou grupos de discussão, como a avaliação da qualidade de vida, o nível de confiança nas instituições, a percepção da corrupção, a performance dos governantes. Ainda que se refiram a dimensões sociais semelhantes, indicadores objetivos e subjetivos podem apontar tendências diferentes. Famílias de baixa renda, quando instadas a avaliar suas condições de vida, podem emitir juízos paradoxalmente mais positivos que uma análise baseada em parâmetros nor mativos e com indicadores objetivos de rendimentos e de infra-estrutura domiciliar. Assim, a opinião da população atendida por um programa é certamente importante, desejável e complementar em qualquer sistemática de monitoramento e avaliação, trazendo subsídios para a correção e melhoria do processo de implementação dos programas e também indícios da 
efetividade social desses programas, especialmente aqueles difíceis de serem mensurados em uma escala quantitativa.

Uma outra lógica de classificação, interessante de se usar na análise de políticas públicas, é a diferenciação dos indicadores entre indicador-insumo, indicador-proces$\mathrm{so}$, indicador-resultado e indicador-impacto (OMS, 1996. Cohen; Franco, 2000). Os indicadores-insumo correspondem às medidas associadas à disponibilidade de recursos humanos, financeiros ou de equipamentos alocados para um processo ou programa que afeta uma das dimensões da realidade social. São tipicamente indicadores de alocação de recursos para políticas sociais o número de leitos hospitalares por mil habitantes, o número de professores por quantidade de estudantes ou ainda o gasto monetário per capita nas diversas áreas de política social. Os indicadores-resultado são aqueles mais propriamente vinculados aos objetivos finais dos prog ramas públicos, que permitem avaliar a eficácia do cumprimento das metas especificadas, como, por exemplo, a taxa de mortalidade infantil, cuja diminuição espera-se verificar com a implementação de um programa de saúde maternoinfantil. Os indicadores-impacto referemse aos efeitos e desdobramentos mais gerais, antecipados ou não, positivos ou não, que decorrem da implantação dos prog ramas, como, no exemplo anterior, a redução da incidência de doenças na infância ou a melhoria do desempenho escolar futura, efeitos decorrentes de atendimento adequado da gestante e da criança recém-nascida em passado recente. Os indicadores-processo ou fluxo são indicadores intermediários, que traduzem, em medidas quantitativas, o esforço operacional de alocação de recursos humanos, físicos ou financeiros (indica- dores-insumo) para a obtenção de melhorias efetivas de bem-estar (indicadores-resultado e indicadores-impacto), como número de consultas pediátricas por mês, merendas escolares distribuídas diariamente por aluno ou ainda homens-hora dedicados a um programa social.

A distinção entre essas dimensões operacionais - insumo, processo, resultado, impacto - pode não ser muito clara em algumas situações, especialmente quando os programas são muito específicos ou no caso contrário, quando os objetivos dos programas são muito gerais. Mas é sempre possível identificar indicadores mais vinculados aos esforços de políticas e programas e aqueles referentes aos efeitos (ou não-efeitos) desses prog ramas.

$\mathrm{Na}$ Figura 2, são apresentados alguns indicadores de acompanhamento de um suposto programa de transferência de renda, cuja finalidade seja a de reduzir a parcela de famílias em condição de indigência, isto é, de famílias com recursos monetários insuficientes para a compra de uma cesta de produtos para a alimentação de seus membros: como indicador-insumo, o volume de recursos do programa, com percentual do orçamento ou em bases per capita; como indicadores-processo, os percentuais de famílias cadastradas pelas prefeituras e daquelas efetivamente atendidas, que podem fornecer elementos para a avaliação da eficiência do programa; como indicadorresultado, a proporção de famílias em situação de indigência, ou com rendimentos abaixo de determinado valor, medida que deveria refletir o grau de eficácia com que o programa atendeu ao objetivo esperado; como indicadores-impacto, a taxa de evasão escolar e a desnutrição infantil, efeitos potenciais do programa implementado que permitem dimensionar a sua efetividade social. 


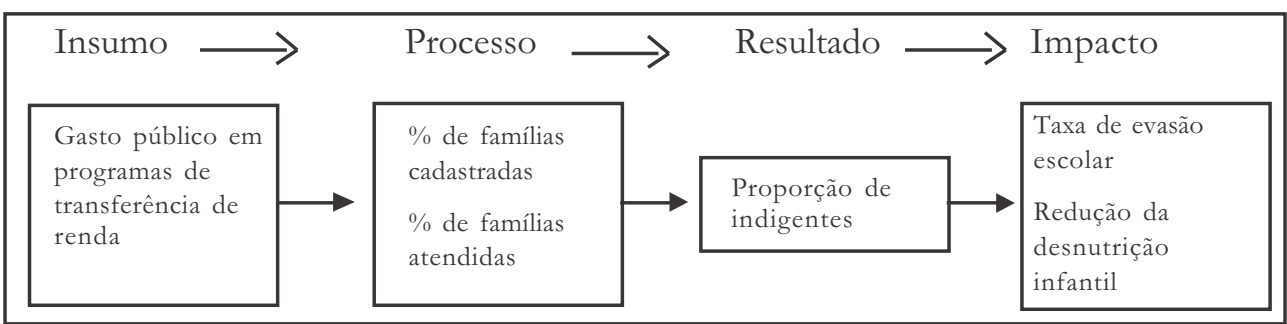

Figura 2: Indicadores de acompanhamento de programas de transferência de renda

Os indicadores podem também ser classificados como simples ou complexos, ou, na terminologia que se tem empregado mais recentemente, como analíticos ou sintéticos. O que os diferencia é, como as denominações sugerem, o compromisso com a expressão mais analítica ou de síntese do indicador. Taxa de evasão escolar, taxa de mortalidade infantil, taxa de desemprego são medidas comumente empregadas para análise de questões sociais específicas no campo da educação, da saúde e do mercado de trabalho. Medidas como Índice de Preços ao Consumidor ou Índice de Desenvolvimento Humano (IDH), por outro lado, procuram sintetizar várias dimensões empíricas da realidade econômica e/ou social em uma única medida. No primeiro caso, o índice de preços corresponde a uma média ponderada de variações relativas de preços de diferentes tipos de produto (alimentação, educação, transporte, etc.). No segundo caso, o IDH corresponde a uma média de medidas derivadas originalmente de indicadores (simples ou analíticos) de escolarização, alfabetização, renda média e esperança de vida.

Há uma idéia subjacente a essa diferenciação entre indicadores analíticos e sintéticos, de que estes últimos, ao contemplarem no seu cômputo um conjunto mais amplo de medidas acerca da realidade social de uma localidade, tenderiam a refletir o comportamento "médio" ou situação "típica" dessa localidade em termos do desenvolvimento humano, qualidade de

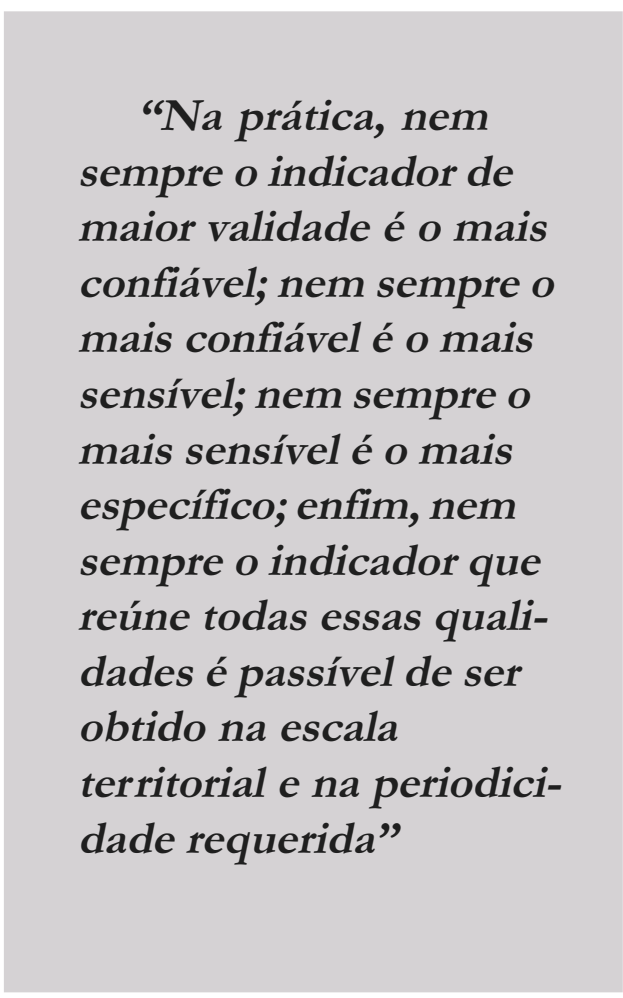

vida, vulnerabilidade social ou outro conceito operacional que lhes deu origem. Como mostrado no Quadro 2, tem havido muitas propostas de indicadores sintéticos no Brasil, com maior ou menor grau de sofisticação metodológica, elaborados por pesquisadores de universidades, órgãos públicos e centros de pesquisa, motivadas, por um lado, pela necessidade de atender às demandas de informação para 
formulação de políticas e tomada de decisões nas esferas públicas e, por outro, pelo sucesso do IDH e seu impacto, nestes últimos 15 anos, na disseminação da cultura de uso de indicadores nos círculos políticos. midade" entre a medida e o conceito original e da usual subsunção do último pela primeira, em que o indicador adquire o status de conceito, como no caso da proporção de famílias com renda abaixo de determinado valor, que passou a designar a popu-

Quadro 2: Alguns dos indicadores sintéticos propostos no Brasil

\begin{tabular}{|c|c|}
\hline Instituição promotora & Índice proposto \\
\hline Fundação João Pinheiro/MG & $\begin{array}{l}\text { IDH-M: Índice de Desenvolvimento Humano Municipal } \\
\text { ICV: Índice de Condições de Vida Municipal }\end{array}$ \\
\hline Fundação CIDE/RJ & $\begin{array}{l}\text { IQM: Índice de Qualidade Municipal - verde } \\
\text { IQM: Índice de Qualidade Municipal - carências } \\
\text { IQM: Índice de Qualidade Municipal - necessidades } \\
\text { habitacionais } \\
\text { IQM: Índice de Qualidade Municipal - sustentabilidade fiscal }\end{array}$ \\
\hline Fundação SEADE/SP & $\begin{array}{l}\text { IPRS: Índice Paulista de Responsabilidade Social } \\
\text { IVJ: Índice de Vulnerabilidade Juvenil } \\
\text { IPVS:Índice Paulista de Vulnerabilidade Social }\end{array}$ \\
\hline $\begin{array}{l}\text { Fundação Economia e } \\
\text { Estatística/RS }\end{array}$ & ISMA: Índice Social Municipal Ampliado \\
\hline $\begin{array}{l}\text { Superintendência de Estudos } \\
\text { Econômicos e Sociais da Bahia } \\
\text { (SEI/BA) }\end{array}$ & $\begin{array}{l}\text { IDS: Índice de Desenvolvimento Social } \\
\text { IDE: Índice de Desenvolvimento Econômico }\end{array}$ \\
\hline $\begin{array}{l}\text { Prefeitura Municipal de Belo } \\
\text { Horizonte/PUC Minas/MG }\end{array}$ & $\begin{array}{l}\text { IQVU: Índice de Qualidade de Vida Urbana } \\
\text { IVS: Índice de Vulnerabilidade Social }\end{array}$ \\
\hline INEP/Cedeplar/NEPO & $\begin{array}{l}\text { IMDE: Indicador Municipal de Desenvolvimento } \\
\text { Educacional }\end{array}$ \\
\hline
\end{tabular}

Contudo, a aplicabilidade dos indicadores sintéticos como instrumentos de avaliação da efetividade social das políticas públicas ou como instrumentos de alocação prioritária do gasto social está sujeita a fortes questionamentos (RYTEN, 2000). Ao partir da premissa de que é possível apreender o "social" por meio da combinação de múltiplas medições dele, não se sabe - ao fim e ao cabo - quais as mudanças específicas ocorridas e qual a contribuição ou o efeito dos programas públicos específicos sobre sua transformação. Além disso, há questionamento acerca do grau de "proxi- lação indigente, que passa fome, etc. (RoCHA, 2002). Há questionamentos acerca do grau de arbitrariedade com que se definem os pesos com os quais os indicadores devem ser ponderados no cômputo da medida final. Há ainda críticas com relação às distorções na seleção de públicos-alvo a que o uso desses indicadores sintéticos podem levar, sobretudo em casos de programas setoriais (GUIMARÃES; JANNUZZI, 2004).

Por mais consistentes que sejam essas críticas, é preciso reconhecer que os indicadores sintéticos acabaram por se legitimar em diversos aspectos. A legitimidade social 
dessas propostas de indicadores tem-se demonstrado pela visibilidade e freqüência que os indicadores sintéticos têm conferido às questões sociais na mídia - pelo for mato apropriado para a síntese jornalística - e à instrumentalização política do movimento social e das ONGs no monitoramento dos programas sociais. $\mathrm{O}$ fato de que alguns desses indicadores foram criados sob encomenda - e mesmo com a participação de gestores públicos e legisladores forte contingenciamento e de corte de verbas no setor público, nos últimos 15 anos. Além disso, como se discute mais à frente, indicadores sintéticos podem ser úteis como instrumentos de tomada de decisão no ciclo de programas sociais.

Assim, além de avaliar a aderência de cada indicador às propriedades relacionadas anteriormente, também pode ser útil fazer uma reflexão sobre a natureza de cada um (Quadro 3), a fim de entender o seu papel

Quadro 3: Identificação da natureza dos indicadores

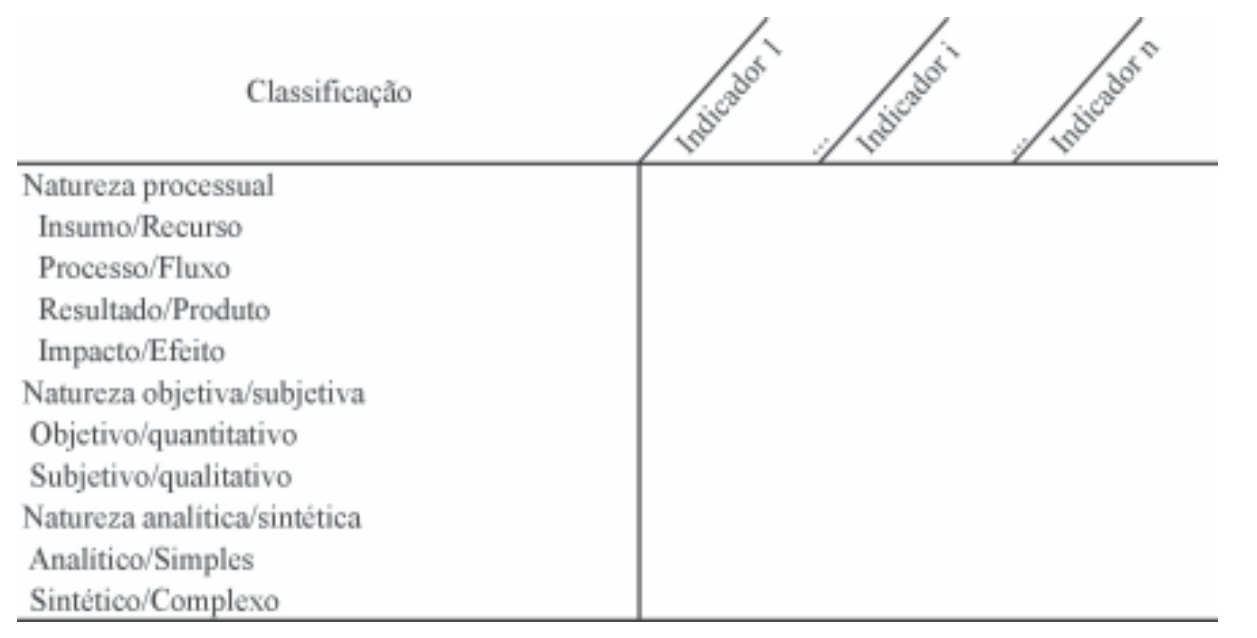

certamente lhes confere legitimidade política. $O$ fato de que os índices acabam aparentemente "funcionando" bem, apontando o que se espera que apontassem - as iniqüidades, os bolsões de pobreza, etc. -, garante-lhes também legitimidade técnica. Também desfrutam de legitimidade científica, já que vários desses projetos têm obtido financiamento de agências nacionais e internacionais de fomento à pesquisa. Por fim, a legitimidade institucional dessas propostas sustenta-se no fato de terem servido de instrumento de garantia do espaço institucional das instituições de estatística e planejamento em um quadro de informativo em um sistema de indicadores para formulação e avaliação de programas sociais, como se dirá na seção seguinte.

\section{Indicadores no ciclo de formula-} ção e avaliação de programas sociais

Apresentado o marco conceitual acerca dos indicadores sociais, passa-se agora à discussão a respeito do uso deles no ciclo de formulação e avaliação de políticas públicas ou programas sociais (Figura 3). Cada etapa do ciclo envolve o uso de um conjunto de indicadores de diferentes naturezas e propriedades, em função das 


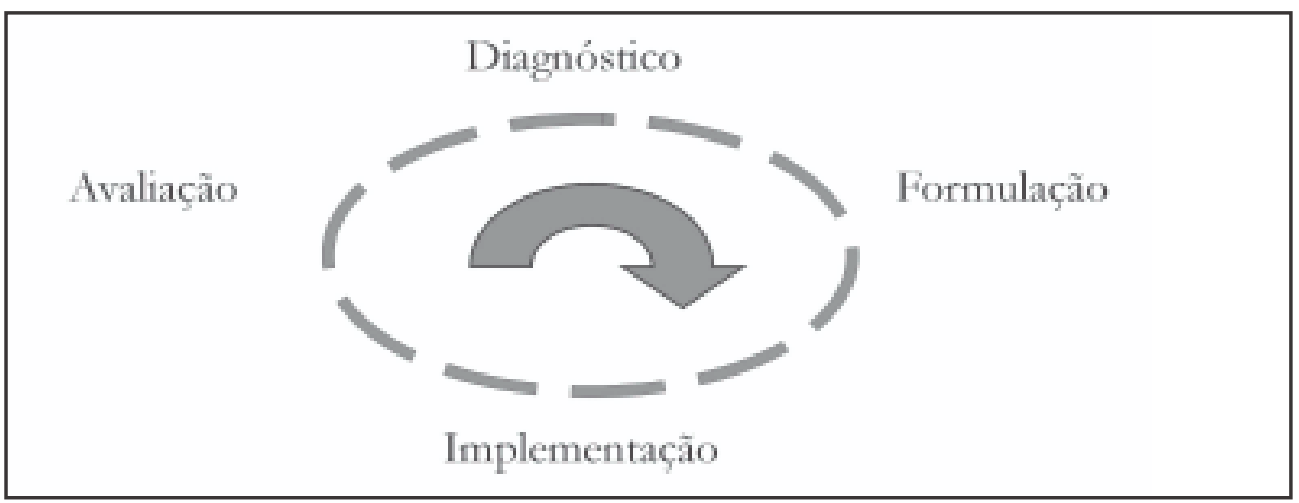

Figura 3: Representação clássica do ciclo de formulação e avaliação de programas sociais

necessidades intrínsecas das atividades aí envolvidas (Quadro 4).

Assim, na etapa de elaboração do diagnóstico para a política ou programa social, são necessários indicadores de boa confiabilidade, validade e desagregabilidade, cobrindo as diversas temáticas da realidade social. Afinal, é preciso ter um retrato tão amplo e detalhado quanto possível acerca da situação social vivenciada pela população para orientar, posteriormente, as questões prioritárias a atender, os formatos dos programas a implementar, as estratégias e ações a desenvolver. Trata-se de caracterizar o marco zero, a partir do qual se poderá avaliar se o programa está provocando as mudanças sociais desejáveis. Os indicadores usados

Quadro 4: Indicadores requeridos em cada etapa do ciclo de programas sociais

\begin{tabular}{|c|c|c|}
\hline Etapa & Tipos e propriedades & Fonte de dados predominante \\
\hline $\begin{array}{l}\text { Elaboração do diagnóstico } \\
\text { Indicadores que permitam } \\
\text { "retratar" a realidade social }\end{array}$ & $\begin{array}{l}\text { Amplo escopo temático } \\
\text { Ampla desagregabilidade geogrifica e } \\
\text { populacional } \\
\text { Validade de Construto } \\
\text { Boa confiabilidade }\end{array}$ & $\begin{array}{l}\text { Censos demográficos } \\
\text { Pesquisas amostrais }\end{array}$ \\
\hline $\begin{array}{l}\text { Formulação de programas } \\
\text { e seleçĩo de altemativas } \\
\text { Indicadores que orientem obje- } \\
\text { tivamente a tomada de decisão }\end{array}$ & $\begin{array}{l}\text { Indicadores sintéticos } \\
\text { Indicadores multicriteriais } \\
\text { Tipologias de situações sociais }\end{array}$ & $\begin{array}{l}\text { Censos demográficos } \\
\text { Pesquisas amostrais }\end{array}$ \\
\hline $\begin{array}{l}\text { Implementação/Execução } \\
\text { Indicadores que permitam } \\
\text { "filmar" o processo de } \\
\text { implementaçiōo dos programas } \\
\text { formulados e a eficiência }\end{array}$ & $\begin{array}{l}\text { Esforço (insumos/processos) } \\
\text { Atualidade/Regularidade } \\
\text { Sensibilidade } \\
\text { Especificidade }\end{array}$ & $\begin{array}{l}\text { Registros administrativos } \\
\text { Registros gerados nos } \\
\text { procedimentos dos próprios } \\
\text { programas }\end{array}$ \\
\hline $\begin{array}{l}\text { Avaliação } \\
\text { Indicadores que permitam } \\
\text { "revelar" a eficícia e efetividade } \\
\text { social dos programas }\end{array}$ & $\begin{array}{l}\text { Resultados e impactos } \\
\text { Distância das metas (déficits } \\
\text { sociais) } \\
\text { Tipologias (boas práticas, ete.) }\end{array}$ & $\begin{array}{l}\text { Pesquisas amostrais } \\
\text { Registros administrativos } \\
\text { Grupos focais } \\
\text { Pesquisas de egressos e de } \\
\text { participantes no programa }\end{array}$ \\
\hline
\end{tabular}


nessa etapa são construídos, em geral, a partir do censo demográfico ou de pesquisas amostrais multitemáticas (como as PNADs), quando os dados do censo já estiverem distantes do momento de elaboração do diagnóstico.

Como observado anteriormente, o Censo 2000 constitui-se em fonte muito rica de indicadores de diagnóstico pelo escopo temático, pela desagregabilidade territorial e populacional e pela comparabilidade inter-regional. Foram levantados, na amostra do censo, mais de 70 quesitos de informação, cobrindo características domiciliares, infra-estrutura urbana, características demográficas e educacionais dos indivíduos, inserção da mão-de-obra, rendimentos, acesso a alguns programas públicos, etc. Os indicadores dessas dimensões analíticas podem ser computados para diversos grupos sociodemográficos (por sexo, raça/cor, estratos de renda, etc.) e escalas territoriais que chegam ao nível de agregações de bairros de municípios (áreas de ponderação, mais propriamente) e até mesmo ao nível de setor censitário (conjunto de cerca de 200 a 300 domicílios na zona urbana, para os quesitos levantados no questionário básico, aplicados em todos os domicílios do País). Por meio de um software de fácil manipulação - Estatcart pode-se extrair estatísticas e cartogramas da quase totalidade dos municípios de médio porte no País, em nível de setor censitário ou áreas de ponderação, como ilustrado na Figura 4.

Essa possibilidade de dispor de informação estatística por setor censitário (ou área de ponderação) não parece ter sido explorada em toda a sua potencialidade por parte de formuladores e gestores de programas sociais, seja no âmbito federal, estadual ou municipal. Quando se trata de fazer diagnósticos sociais mais detalhados territorialmente, empregam-se, em geral, indicadores médios computados para os municípios, "escondendo-se" os bolsões de iniqüidades presentes dentro de cada um dos municípios brasileiros. Os indicadores médios de rendimentos ou de infra-estrutura urbana do Município de São Paulo são, por exemplo, bem melhores que a média geral dos municípios brasileiros. Contudo, se os indicadores forem computados em nível de setores censitários, poder-se-á constatar no território paulistano a diversidade de situações de condições de vida encontrada pelo território nacional, ou seja, é possível encontrar bolsões de pobreza na capital paulistana com características de alguns municípios do Nordeste ${ }^{2}$.

Um dos recursos que têm auxiliado na elaboração e apresentação de diagnósticos sociais é a proposição de tipologias, agrupamentos ou arquétipos sociais, usados para classificar unidades territoriais segundo um conjunto específico de indicadores sociais e, portanto, apontando os déficits de serviços públicos, de programas específicos, etc. O Índice Paulista de Resposabilidade Social é um exemplo nesse sentido, ao classificar os municípios paulistas em cinco grupos, de acordo com os níveis observados de indicadores de saúde, escolaridade e porte econômico municipal (SEADE, 2002).

Além dos indicadores multitemáticos para "retratar" as condições de vida, referentes à saúde, à habitação, ao mercado de trabalho, etc., também devem fazer parte do diagnóstico os indicadores demográficos, em especial, aqueles que permitem apresentar as tendências de crescimento populacional passado e as projeções demográficas futuras (que dimensionam os públicos-alvo dos diversos programas em termos de idade e sexo no futuro). As mudanças demográficas foram bastante 
Chefes sem rendimento ou até 1 s.m.
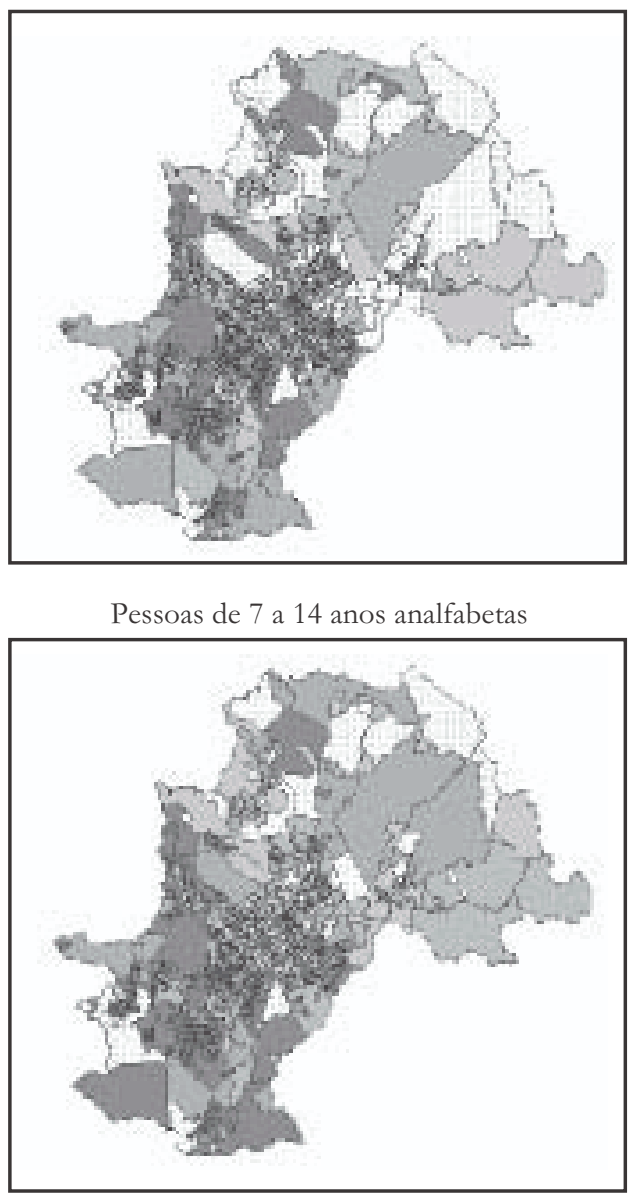

Chefes sem instrução ou até 1 ano de estudo

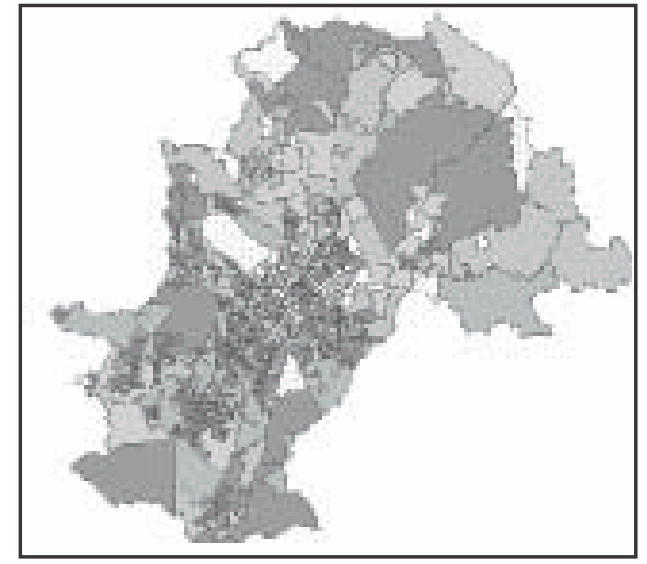

Domicílios urbanos sem acesso à rede de água

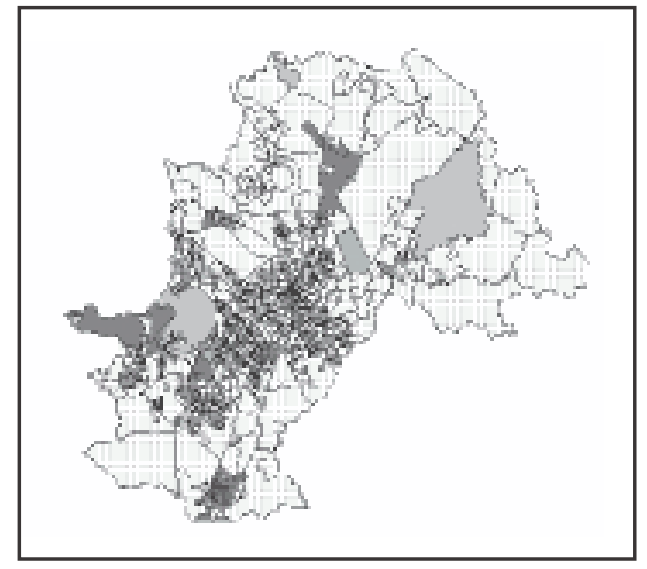

Figura 4: Cartogramas com indicadores sociais referidos em nível de setor censitário Campinas/SP - 2000

intensas pelo País nos últimos 30 anos, com impacto significativo e regionalmente diferenciado sobre a demanda de vagas escolares, postos de trabalho, etc. (MARTINE; CarvalHo; Árias, 1994).

$\mathrm{Na}$ segunda etapa do ciclo de formulação e seleção de programas, requer-se um conjunto mais reduzido de indicadores, selecionados a partir dos objetivos norteadores dos programas definidos como prioritários pela agenda político-social vigente. Já se conhecem, em tese, por meio do diagnóstico, os bolsões de pobreza, as áreas com maior déficit de serviços urbanos, com maior parcela de crianças fora da escola, com maior número de responsáveis sujeitos ao desemprego. Nessa etapa, requer-se definir, a partir da orientação político-governamental, a natureza dos programas, as questões sociais prioritárias a enfrentar, os públicos-alvo a atender.

É nessa fase que os indicadores sintéticos já mencionados podem ter maior aplicação, na medida em que oferecem ao gestor uma medida-síntese das condições de vida, da vulnerabilidade, 
do desenvolvimento social de municípios, estados ou de outra unidade territorial em que há implementação de programas. O IDH-municipal foi, por exemplo, o indicador empregado pelo Programa Comunidade Solidária para selecionar os municípios para suas ações, o que certamente representou um avanço em termos de critério técnico-político de priorização. Contudo, a escolha desse indicador acabou por excluir do programa todas as cidades médias e populosas do Sudeste, já que suas medidas sociais médias - calculadas para a totalidade do município - eram sempre mais altas que as dos municípios do Norte e Nordeste. Se fosse usado um indicador calculado para domínios submunicipais (setor censitário, bairros, áreas de ponderação, etc.), os municípios do Sudeste certamente teriam bolsões que se enquadrariam entre os públicos-alvo prioritários do programa.

Esse exemplo deixa claro a importância do diagnóstico microespacializado comentado anteriormente, em especial o realizado em nível de setor censitário. É possível, dessa forma, não só garantir maior precisão e eficiência na alocação dos programas que devem ser focalizados, como também acompanhar, posteriormente, os seus efeitos. Além disso, o uso do setor censitário (ou área de ponderação) garante, em alguma medida, a compatibilização dos quantitativos populacionais de cada pequena área, amenizando os efeitos potencialmente destoantes da tomada de decisão baseada em indicadores expressos em termos relativos. Dois municípios podem ter, por exemplo, percentual similar de famílias indigentes, mas totais absolutos de indigentes muito distintos. Municípios populosos podem apresentar cifras relativamente mais baixas de indigentes, mas ainda assim podem reunir totais absolutos bastante significativos. Em qual município devem-se priorizar as ações de programas de transferência de renda: naquele em que a intensidade de indigência é elevada ou naquele em que o quantitativo de indigentes é maior? Quando se têm indicadores calculados para áreas com totais populacionais mais compatíveis, os rankings de priorização baseados em indicadores relativos ou absolutos diferem pouco $^{3}$.

Idealmente, a tomada de decisão com relação aos públicos-alvo a serem priorizados deve-se pautar em um indicador mais específico e válido para o programa em questão, mais relacionado aos seus objetivos, como a taxa de mortalidade infantil em programas de saúde maternoinfantil, o déficit de peso ou altura em programas de combate à fome ou a proporção de domicílios com baixa renda em programas de transferência de renda. Se vários indicadores devem ser usados e os critérios de elegibilidade referem-se a variáveis existentes no censo demográfico, é possível fazer processamentos específicos, de forma relativamente rápida, por meio de um pacote estatístico (com os microdados do censo em 16 CD-ROMs) ou mesmo por meio de uma ferramenta disponibilizada pela Internet (Banco Multidimensional de Estatísticas) no sítio do IBGE. Um desses indicadores construídos pelo cruzamento de variáveis do Censo 2000 é o trazido na última tabela da publicação Indicadores municipais do IBGE (2002). Trata-se de um indicador combinado - construído a partir do cruzamento simultâneo dos diversos critérios -, representando a proporção dos domicílios particulares permanentes que não têm escoadouros ligados à rede geral ou fossa séptica, não são servidos de água por rede 
geral, não têm coleta regular de lixo, seus responsáveis (chefes) têm menos de quatro anos de estudo e rendimento médio mensal até dois salários mínimos. Esse indicador - batizado informalmente de Indicador de Déficit Social - pode ser calculado também por áreas de ponderação do censo e tem-se mostrado com grande poder de discriminação e validade em representar situações de carências de serviços públicos básicos pelo território nacional. decisão seja pautada com base nos critérios (indicadores) considerados relevantes para o programa em questão pelos agentes decisores e que a importância dos critérios seja definida por eles, em um processo de interatividade com outros atores técnicopolíticos. Alguns algoritmos que implementam a técnica produzem soluções hierarquizadas - como um indicador sintético e robustas, não dependentes da escala de medida ou dispersão das variáveis (Figura 5).

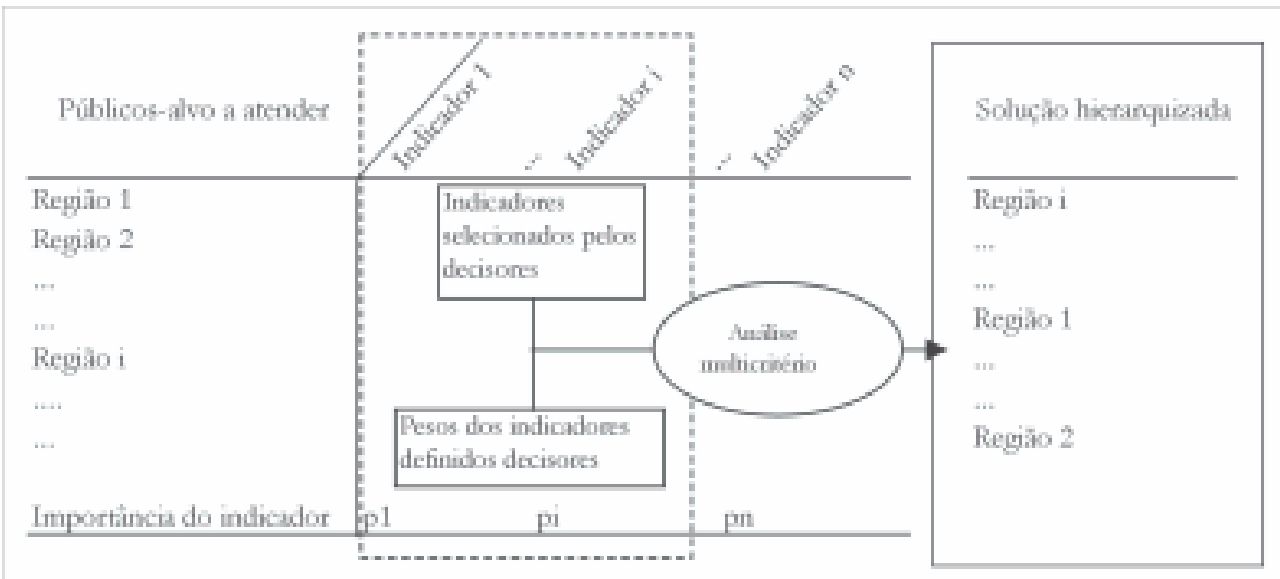

Figura 5: Análise multicritério para tomada de decisão com base em indicadores sociais

Em alguns casos de programas intersetoriais que envolvem esforços de equipes de diferentes áreas e o alcance de vários objetivos, pode ser interessante tomar a decisão acerca das áreas prioritárias de implantação dos programas a partir da combinação de vários critérios (indicadores). Nesse caso, pode-se empregar a análise multicritério, técnica estruturada para tomada de decisões em que interagem vários agentes, cada um com seus critérios e juízos de valor acerca do que é mais importante considerar na decisão final (EnssLin, 2001). A vantagem do uso dessa técnica em relação a outras, como o emprego de indicadores sintéticos, é que ela permite que a
$\mathrm{Na}$ etapa de implementação e execução dos programas, são necessários indicadores de monitoramento, que devem primar pela sensibilidade, especificidade e, sobretudo, pela periodicidade com que estão disponíveis. Esse é um grande problema, como já se observou anteriormente, em especial se se necessita de indicadores em escala municipal. As informações produzidas pelas agências estatísticas não são, em geral, específicas para os propósitos de monitoramento de programas, seja na escala territorial desejada, seja na regularidade necessária.

Contudo, procurando atender à demanda por informações municipais mais 
periódicas, o IBGE tem realizado, de forma mais regular, a Pesquisa Nacional de Assistência Médico-Sanitária (AMS), a Pesquisa de Informações Básicas Municipais (MUNIC) e a Pesquisa Nacional de Saneamento Básico (PNSB). A AMS corresponde a um censo de estabelecimentos de saúde no País, identificando volume e qualificação de pessoal, equipamentos e outros recursos disponibilizados para atendimento médico-sanitário da população. Com isso, pode-se ter uma idéia mais clara e precisa do nível e da diversidade da oferta de serviços de saúde pelo País, por meio da construção de indicadores de esforços de políticas na área de saúde. A MUNIC contempla, anualmente, o levantamento de conjunto amplo de informações nas prefeituras dos mais de 5 mil municípios brasileiros. Nessa pesquisa, levantam-se dados sobre a estrutura administrativa, o nível de participação e formas de controle social (existência de conselhos municipais), a existência de legislação e instrumentos de planejamento municipal (como a institucionalização do plano de governo, do plano plurianual de investimentos, do plano diretor e da lei de parcelamento do solo), a disponibilidade de recursos para promoção da justiça e segurança (existência de delegacia da mulher, juizados de pequenas causas, etc.), além da existência de equipamentos específicos de comércio, serviços da indústria cultural e de lazer, como bibliotecas públicas, livrarias, jornais locais e ginásios de esporte. Essa pesquisa permite, pois, construir indicadores que permitem retratar o grau de participação e controle popular da ação pública e caracterizar o estágio de desenvolvimento institucional das atividades de planejamento e gestão municipal pelo País. A PNSB veio complementar esse quadro informacional sobre os municípios brasileiros com a coleta de dados sobre abastecimento de água, esgotamento sanitário, limpeza urbana e sistema de drenagem urbana. Pode-se, assim, dispor de outros indicadores mais informativos sobre a estrutura e qualidade dos serviços de infra-estrutura urbana, que não se limitam a apontar o grau de cobertura populacional atendida. Com os dados levantados nessa pesquisa, é possível construir indicadores do volume de água

"Dois municípios podem ter percentual similar de familias indigentes, mas totais absolutos de indigentes muito distintos. Em qual município devem-se priorizar as ações de programas de transferência de renda: naquele em que a intensidade de indigência é elevada ou naquele em que $o$ quantitativo de indigentes é maior?”

ofertada per capita, do tipo de tratamento e do volume da água distribuída à população, do volume e destino do esgoto e lixo coletado, entre outros aspectos.

Há também esforços louváveis de várias instituições públicas, além do IBGE, em disponibilizar infor mações de seus cadastros e registros de forma mais periódica, fato que se deve não só à necessidade de monitoramentos da ação governamental, 
mas também às facilidades que as novas tecnologias de informação e comunicação têm proporcionado. Os órgãos estaduais de estatística, os Ministérios da Saúde, da Educação, do Trabalho, do Desenvolvimento Social, da Previdência Social, das Cidades e a Secretaria do Tesouro Nacional disponibilizam pela Intemet informações bastante específicas - em escopo temático e escala territorial-a partir de seus registros e sistemas de controle internos, que podem ser úteis para a construção de indicadores de monitoramento de programas (Quadro 5).
A lógica do acompanhamento de programas requer a estruturação de um sistema de indicadores que, além de específicos, sensíveis e periódicos, permitam monitorar a implementação processual do programa na lógica insumo-processoresultado-impacto, isto é, são necessários indicadores que permitam monitorar o dispêndio realizado por algum tipo de unidade operacional prestadora de serviços ou subprojeto; o uso operacional dos recursos humanos, financeiros e físicos; a geração de produtos e a percepção dos efeitos sociais

Quadro 5: Algumas das fontes oficiais para atualização periódica de indicadores

\begin{tabular}{|c|c|c|}
\hline Fonte & Sitio & Conteúdo \\
\hline IBGE & wwwilige govbe & 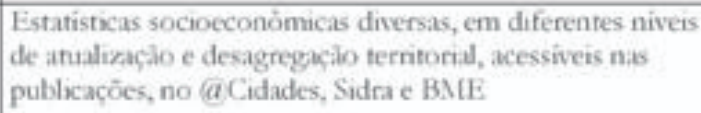 \\
\hline $\begin{array}{l}\text { Orgàos estaduais } \\
\text { de estatistica }\end{array}$ & www:unipes orgbr & $\begin{array}{l}\text { Pelo sítio da Associaçio Nacional das Institusçōes de } \\
\text { Planejamento, Pesquasa e Estatistica, pode-se acessar os } \\
\text { óngios estaduass e as suas informaçōes }\end{array}$ \\
\hline $\begin{array}{l}\text { Alinistério da } \\
\text { Saúde }\end{array}$ & www.darasus.govbr & $\begin{array}{l}\text { Estatisticis de mortalidade por causas } \\
\text { Atendimentos no SUS } \\
\text { Registro de vacinaçōes }\end{array}$ \\
\hline $\begin{array}{l}\text { Mlinistêrio da } \\
\text { Educiçio }\end{array}$ & www:mepgonster & $\begin{array}{l}\text { Estatisticas educacionais } \\
\text { Docentes e equipamentos } \\
\text { Avaliaçâo de desempenho educacional }\end{array}$ \\
\hline $\begin{array}{l}\text { Ministério do } \\
\text { Trabalho }\end{array}$ & www.mte-gowbr & $\begin{array}{l}\text { Estatísticas mensais do Cidastro Geral de Empregados e } \\
\text { Desempregados } \\
\text { Relaçĩo Anual das Informaçồes Sociais }\end{array}$ \\
\hline $\begin{array}{l}\text { Ministétio do } \\
\text { Desenvolvimento } \\
\text { Social }\end{array}$ & www mids gavbe & $\begin{array}{l}\text { Indicadores de pobrezat e indigencia } \\
\text { Acesso tos programas de transferincia de renda }\end{array}$ \\
\hline $\begin{array}{l}\text { Ministério da } \\
\text { Previdìncia Socral }\end{array}$ & www:mpas.gowbr & $\begin{array}{l}\text { Beneficios e auxilios concedidos } \\
\text { Contribuintes } \\
\text { Acidentes de trabalho }\end{array}$ \\
\hline $\begin{array}{l}\text { Ministério das } \\
\text { Cidades }\end{array}$ & wwweidades.govbr & $\begin{array}{l}\text { Indicadores urbanos e sancamento } \\
\text { Déficit habitacional }\end{array}$ \\
\hline $\begin{array}{l}\text { Secretaria do } \\
\text { Tesouro Nacional }\end{array}$ & wwwstn.fivendi.gov.br & $\begin{array}{l}\text { Transferíncias de recursos: } \\
\text { Execuçào orçamentiria } \\
\text { Receitas e despesas municipas }\end{array}$ \\
\hline
\end{tabular}


mais amplos dos programas. Assim, a distinção entre a terceira e a quarta etapas do ciclo de programas pode ser menos evidente que nas demais, sobretudo em programas de longa duração, isto é, monitoramento e avaliação de programas são termos cunhados para designar procedimentos de acompanhamento de programas, focados na análise da sua eficiência, eficácia e efetividade (COHEN; FrANCO, 2000). Monitoramento e avaliação são processos analíticos organicamente articulados, sucedendo-se no tempo, com o propósito de subsidiar o gestor público com informações acerca do ritmo e da forma de implementação dos programas (indicadores de monitoramento) e dos resultados e efeitos almejados (indicadores de avaliação).

Como atividade de monitoramento ou de avaliação, é importante analisar os indicadores de resultados a partir dos indicadores de esforços e recursos alocados, o que permite o dimensionamento da eficiência dos prog ramas. O emprego da Análise Envoltória de Dados (DEA) pode representar grande avanço metodológico nesse sentido (LINs; MEZA, 2000). A DEA é uma técnica derivada dos métodos de pesquisa operacional que visa à identificação das unidades de operação mais eficientes, tendo em vista como os recursos (retratados por vários indicadores de insumo) são utilizados para gerar os resultados finais (medidos por diversos indicadores-resultados), considerando as condições estruturais de operação dos programas. Determinados programas implementados em regiões mais pobres, poderão não ter resultados tão promissores como em outras mais desenvolvidas. Assim, é preciso avaliar a eficiência dos programas em função não apenas em relação ao resultado obtido e à quantidade de recursos alocados, mas considerando as dificuldades ou potencialidades existentes na região em que os programas estão funcionando. O que tor na essa técnica particularmente interessante de ser aplicada é que se podem considerar os recursos e resultados como vetores de indicadores em suas escalas originais e não como variáveis representando valores monetários de custos e benefícios.

Como ilustra a Figura 6, um programa de saúde deve ser avaliado em relação aos diversos resultados que produz em termos de redução das taxas de mortalidade e morbidade, a partir dos recursos alocados (médicos por mil habitantes) e serviços de saúde prestados (consultas atendidas), considerando as condições estruturais de vida existentes em cada local de sua implementação (indicadores de renda e infra-estrutura de saneamento). Pela técnica é possível identificar as "boas práticas" ou benchmarks reais, isto é, unidades de implementação do programa em que os resultados são, de fato, compatíveis com o nível de esforço empreendido e de recursos gastos.

Os indicadores de desembolso de recursos e produtos colocados à disposição da população - construídos a partir de registros próprios da sistemática de controle e gerenciamento dos programas - podem permitir uma avaliação indireta da eficácia dos programas no alcance das metas estabelecidas, quando as estatísticas públicas ou os dados administrativos de ministérios e secretarias estaduais não forem mais específicos e periódicos na escala territorial desejada. $\mathrm{Na}$ falta de pesquisas amostrais regulares que contemplem temáticas relativas, por exemplo, ao consumo de produtos culturais e aos hábitos de lazer - ainda não incorporadas na agenda político-social nacional de forma imperativa -, a eficácia de programas na área, como os de fomento à leitura, terá 


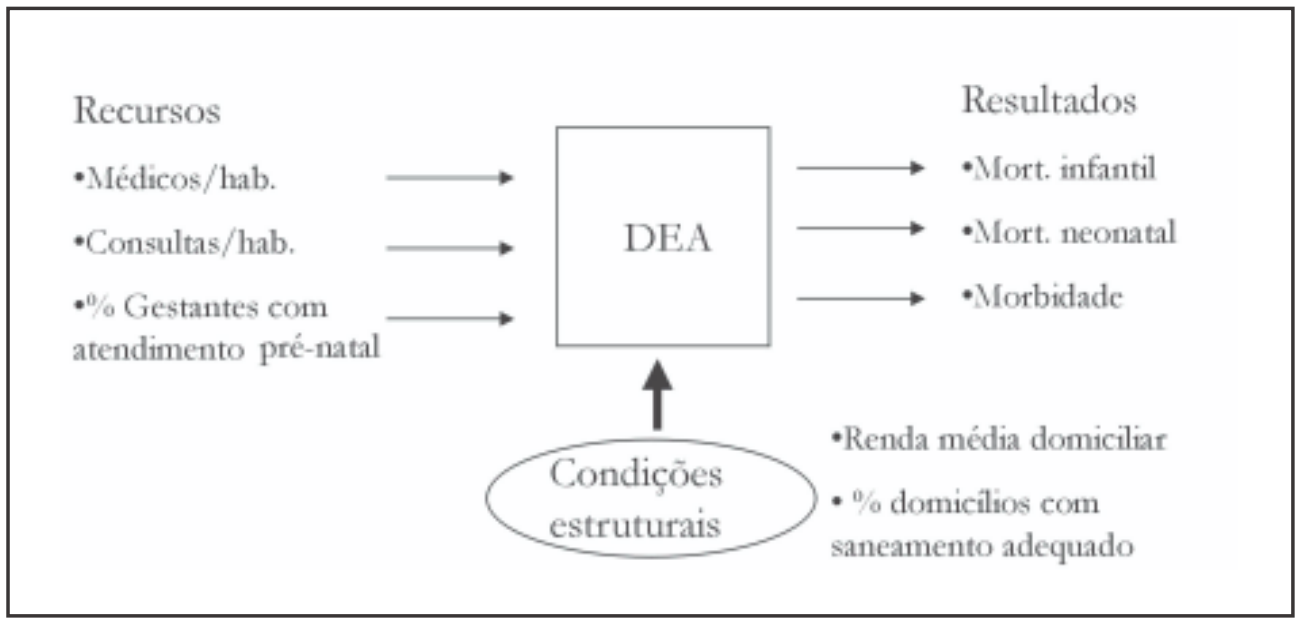

Figura 6: Aplicação da Análise Envoltória de Dados na avaliação de programas em saúde

de ser inferida a partir dos produtos previstos na ações desencadeadas, como o volume de livros distribuídos às escolas e bibliotecas. Nesse caso, indicadores de resultados mais válidos para avaliar a eficiência do programa, como número médio de livros lidos no último ano, por exemplo, são apenas ocasionalmente levantados pelo IBGE ou pela Câmara Brasileira do Livro.

Outra demanda no ciclo de programas, em particular na etapa de avaliação, é a identificação dos seus impactos. Para tanto, devem-se empregar indicadores de diferentes naturezas e propriedades, de forma a conseguir garantir tanto quanto possível a vinculação das ações do programa com as mudanças percebidas, ou não, nas condições de vida da população, tarefa sempre difícil de ser realizada (Roche, 2002). Em primeiro lugar, a menos que a realidade social vivenciada antes do início do programa (marco zero) fosse muito trágica, ou que o programa tenha recebido recursos muito expressivos para serem gastos em curto espaço de tempo, não se pode esper ar que os produtos e resultados gerados no âmbito dele possam ser imediatamente impactantes sobre a sociedade. Programas de transferência de renda ou de distribuição de leite ou cestas básicas em periferias de grandes cidades do Sudeste proporcionam impactos sociais comparativamente menos intensos e rápidos que programas de investimento em saneamento básico, por exemplo, no que diz respeito às condições de mortalidade infantil. Contudo, ao longo do tempo, a transferência de renda ou a distribuição de produtos estará contribuindo para a melhoria da nutrição de crianças, garantindo ganhos adicionais contra a mortalidade infantil, assim como, mais a médio prazo, para a melhoria do seu desempenho escolar. Esse exemplo revela, pois, a dificuldade de se atribuírem os efeitos de programas específicos sobre as mudanças estruturais das condições sociais, dificuldade que, paradoxalmente, cresce à medida que tais transformações - e os impactos - tendem a se tornar mais evidentes. A dificuldade é ainda maior quando se observam problemas de descontinuidades e de implementação nos programas públicos. 
De modo a perceber mais claramente os impactos dos programas, deve-se buscar medidas e indicadores mais específicos e sensíveis aos efeitos por eles gerados. Uma das formas de se operacionalizar isso é avaliando efeitos sobre grupos específicos da população, seja em termos de renda, idade, raça, sexo ou localização espacial. Se os programas têm públicos-alvo preferenciais, localizados em determinadas regiões ou estratos de renda, deve-se não só buscar indicadores de impacto que privilegiem a sua avaliação do conjunto da população, que pode estar, inclusive, sob o risco de efeitos estruturais mais gerais (que podem não afetar o público-alvo na mesma intensidade), mas também desenvolver estratégias metodológicas avaliativas de natureza qualitativa, com pesquisas de opinião ou grupos de discussão, incorporando indicadores subjetivos na avaliação. Nesse sentido, os impactos podem ser avaliados em uma perspectiva mais restrita ou mais ampla, considerando o tamanho da população afetada, o espaço de tempo considerado para a referência dos indicadores e a natureza mais objetiva ou subjetiva dos impactos percebidos pela população.

\section{Considerações finais}

Uma das grandes dificuldades atuais no acompanhamento de programas públicos é dispor de informações periódicas e específicas acerca do processo de sua implementação e do alcance dos resultados e do impacto social que tais programas estão tendo nos segmentos sociodemográficos ou nas comunidades focalizadas por eles. Seja da perspectiva da avaliação formativa, isto é, aquela com os propósitos de acompanhar e monitorar a implementação de programas, a fim de verificar se os rumos traçados estão sendo seguidos e permitir intervenções corretivas, seja da perspectiva da avaliação somativa, isto é, aquela mais ao final do processo de implementação, com propósitos mais amplos e meritórios (CANO, 2002), o gestor de programas sociais defronta-se com a dificuldade de obter dados válidos, específicos e regulares para seus propósitos.

Se é fato que as informações produzidas pelas a gências estatísticas são, em boa medida, pouco específicas para os propósitos de monitoramento de programas, não provendo informação na escala territorial desejada ou na regularidade necessária, é também verdade que elas podem-se prestar à elaboração de diagnósticos bastante detalhados em escopo e escala, como no caso das informações provenientes dos censos demográficos. As informações produzidas no âmbito dos processos administrativos dos ministérios e das secretarias estaduais e municipais podem também suprir boa parte da demanda de dados para a construção de indicadores periódicos de monitoramento, requerendo, contudo, algum "retrabalho" de "customização" em função das necessidades de delimitação territorial dos programas, desde que exista um código de localização da escola, do posto de saúde, da delegacia, etc.

De qualquer forma, as estatísticas e os dados do IBGE e de outros órgãos públicos dificilmente atenderão todas as necessidades informacionais requeridas para o monitoramento e a avaliação de programas públicos mais específicos. Assim, é necessário, quando da formulação desses programas, prever a organização de procedimentos de coleta e tratamento de informações específicas e confiáveis em todas as fases do ciclo de implementação, que possam permitir a construção dos indicadores de monitoramento desejados.

(Artigo recebido em maio de 2005. Versão definitiva em junho de 2005) 


\section{Notas}

* Texto submetido à editoria da Revista do Serviço Público em que se procura compilar e reorganizar idéias expostas em três oportunidades anteriores (Jannuzzi , 2001, 2002. Guimarães; Jannuzzi, 2004), a partir das experiências de capacitação de técnicos de ONGs e gestores do setor público nos cursos de extensão de "Indicadores Sociais e Políticas Públicas", desenvolvidos no âmbito do convênio ENCE/IBGE e Fundação FORD, e nos cursos de for mação da Escola Nacional de Administração Pública ao longo de 2003 e 2004.

${ }^{1}$ Dada a inexistência e desorganização dos cadastros nos municípios brasileiros, os censos demográficos acabam levantando um conjunto muito amplo de informações, o que o torna ainda mais custoso e complexo.

${ }^{2}$ De fato, é o que o Índice Paulista de Vulnerabilidade Social - calculado por setor censitário permite constatar (vide em: www.seade.gov.br).

${ }^{3}$ Vale observar, contudo, que os setores censitários apr esentam variabilidade significativa em termos de quantitativos populacionais pelos municípios brasileiros.

\section{Referências bibliográficas}

Cano, I. Avaliação de programas sociais. Rio de Janeiro: FGV, 2002.

CArley, Michael. Indicadores sociais: teoria e prática. Rio de Janeiro: Zahar, 1985.

Costa, F.L.; Castanhar, J. C. Avaliação de programas públicos: desafios conceituais e metodológicos. Revista Brasileira de Administração Pública, Rio de Janeiro, v. 37, n.5, p.:969992, 2003.

Cohen, E.; Franco, R. Avaliação de projetos sociais. Petrópolis: Vozes, 2000.

EnssLin, Leonardo et al. Apoio à decisão: metodologias para estruturação de problemas e avaliação multicritério de alternativas. Florianópolis, SC: Insular, 2001. v. 1. 296 p.

GARCiA, R.C. Subsídios para organizar avaliações da ação governamental. Planejamento e Políticas Públicas, Brasília, v. 23, n. 7, p. 70, 2001.

Guimarães, J. R. S.; J AnnuZzi, P. M. IDH, indicadores sintéticos e suas aplicações em políticas públicas: uma análise crítica. In:EnCONTRo Nacionalde Estudos PopulacionAis, 14. Anais... Caxambu, 2004.

IBGE. Indicadores sociais municipais. Rio de Janeiro: 2002.

Jannuzzi, P. M. Indicadores sociais no Brasil: conceitos, fonte de dados e aplicações. Campinas: Alínea, 2001.

. Considerações sobre o uso, mau uso e abuso dos indicadores sociais na for mulação e avaliação de políticas públicas municipais. Revista de Administração Pública, Rio de Janeiro, v. 36, n. 1, p. 51-72, jan./ fev. 2002.

Lins, M.E; Meza, L. A. Análise envoltória de dados e perspectivas de integração no ambiente de apoio à decisão. Rio de Janeiro: COPPE/UFRJ, 2000. 
Martine, G.; Carvalho, J. A. M.; Árias, A. R. Mudanças recentes no padrão demográfico brasileiro e implicações para a agenda social. Brasília, IPEA, 1994. (Texto para Discussão n. 345)

Mites, I. Social indicators for human development. New York: St. Martin's Press, 1985.

NAÇÕES UNIDAs. Handbook of social indicators. Nova York: 1988.

OMS. Catalogue of health indicators. Genebra: 1996.

Rocha, S. Pobreza: do que se trata afinal. Rio de Janeiro: FGV, 2003.

Roche, C. Avaliação de impacto dos trabalhos de ONGs. São Paulo: Cortez, 2002.

RYTEN, J. Should there be a human development index? Statistique, Développement et Droits de l'Homme Seminar, Montreaux, Setembre, 2000.

SEADE. Monitoração de prioridades de desenvolvimento com equidade social. In: KeInert, Tânia; Karruz, Ana Paula (Orgs.). Qualidade de vida: observatórios, experiências e metodologias. São Paulo: Annablume; Fapesp, 2002. 


\section{Resumo - Resumen - Abstract}

Indicadores para diagnóstico, monitoramento e avaliação de programas sociais no Brasil Paulo de Martino Jannuzzi $i$

O objetivo do texto é discutir as potencialidades e limitações do uso das informações estatísticas produzidas pelo IBGE e os registros administrativos de órgãos públicos para a construção de indicadores para diagnóstico, monitoramento e avaliação de programas sociais no Brasil. Inicia-se com uma apresentação sobre os aspectos conceituais básicos acerca dos indicadores sociais, suas propriedades e formas de classificação. Depois, discute-se uma proposta de estruturação de um sistema de indicadores para subsidiar o processo de formulação e avaliação de políticas e programas públicos no País. Conclui-se o texto advogando-se a necessidade de estruturar sistemas de indicadores que se apóiem na busca de informações já existentes em fontes secundárias e na produção de dados no âmbito dos próprios programas.

Palavras-chave: indicadores, monitoramento, políticas sociais

\section{Los indicadores para formulación y evaluación de programas sociales en Brasil}

Paulo de Martino Jannuzzi

$\mathrm{El}$ artículo discute las potencialidades y las limitaciones del uso de la información estadística producida por el IBGE y los registros administrativos de las agencias públicas para la construcción de los indicadores para la diagnosis, seguimiento y evaluación de programas sociales en Brasil. Comienza presentando la base conceptual referente a los indicadores sociales, sus características y los sistemas de clasificación. Después, presenta un marco del sistema de indicadores para subsidiar el proceso de formulación y evaluación de programas públicos. El artículo concluye proponiendo la necesidad de construir sistemas de indicadores basados en fuentes secundarias de datos y también en los datos primarios recogidos en las etapas de los programas.

Palabras clave: indicadores, monitoreo, políticas sociales

\section{Indicators for social policy making and evaluation in Brazil}

Paulo de Martino Jannuzzi

The paper discusses the potentialities and limitations of the use of statistical information produced by the IBGE and the administrative registers of public agencies for the construction of indicators to be used in the diagnosis, monitoring and evaluation of social programs in Brazil. It begins by presenting the conceptual basis for understanding the social indicators, their properties and classification systems. It then outlines a framework of a system of indicators to support the process of formulation and evaluation of public programs. The paper concludes by advocating the need to structure systems of indicators based on secondary sources of data and also on primary data collected in the scope of the programs.

Key words: indicators, monitoring, social policies

Paulo de Martino Jannuzzi

Assessor da Diretoria Executiva do SEADE, professor da ENCE/IBGE, pesquisador CNPq no projeto de pesquisa "Infor mação estatística no ciclo de formulação, monitoramento e avaliação de políticas públicas no Brasil”, com recursos do CNPq (Proc. 307101/2004-5). Contato: pjannuzzi@ibge.gov.br 